\title{
Labor Induction with Transcervical Catheter versus Oral Misoprostol in Primiparous Women and Women with an Unripe Cervix
}

\author{
Anna Thorbiornson', Tomislav Vladic ${ }^{2}$, Ylva Vladic Stjernholm ${ }^{2 *}$ \\ ${ }^{1}$ Medical Educational Programme in Gynecology and Obstetrics, Karolinska University Hospital and Karolinska \\ Institute, Stockholm, Sweden \\ ${ }^{2}$ Department of Women's and Children's Health, Karolinska University Hospital, Stockholm, Sweden \\ Email: *ylva.vladic-stjernholm@karolinska.se
}

Received 28 September 2015; accepted 28 November 2015; published 4 December 2015

Copyright (C) 2015 by authors and Scientific Research Publishing Inc.

This work is licensed under the Creative Commons Attribution International License (CC BY). http://creativecommons.org/licenses/by/4.0/

(c) (i) Open Access

\begin{abstract}
Objective: To compare labor induction with transcervical catheter to oral misoprostol treatment in primiparous women and women with an unripe cervix, who are at high risk for unsuccessful labor induction. Study Design: A retrospective study was carried out in a university hospital in Sweden. Primary outcomes were vaginal birth within 24 hours and the cesarean section rate. Secondary outcomes were the induction to vaginal delivery interval, chorioamnionitis and neonatal asphyxia. Results: Vaginal birth within 24 hours was obtained more frequently after catheter compared with misoprostol in primiparous women $(p<0.001)$ and women with Bishop scores $3-4(p<0.001)$, but not in women with Bishop scores 0 - $2(p=0.07)$. The cesarean section rates were comparable in all groups $(p>0.05)$. The induction to vaginal delivery interval was 8 - 12 hours shorter after catheter $(p<0.001)$. The rates of chorioamnionitis and newborns with an Apgar score $<7$ at 5 min were comparable ( $p>0.05)$. Conclusion: Labor induction with transcervical catheter resulted in a higher rate of vaginal birth within 24 hours and an 8 - 12 hour shorter induction to vaginal delivery interval compared to treatment with oral misoprostol. This was obtained without increasing the rates of cesarean section, chorioamnionitis or neonatal asphyxia.
\end{abstract}

\section{Keywords}

Cervical Ripening, Transcervical Catheter, Oral Misoprostol, Vaginal Birth, Cesarean Section

\footnotetext{
${ }^{*}$ Corresponding author.
}

How to cite this paper: Thorbiornson, A., Vladic, T. and Stjernholm, Y.V. (2015) Labor Induction with Transcervical Catheter versus Oral Misoprostol in Primiparous Women and Women with an Unripe Cervix. Open Journal of Obstetrics and Gynecology, 5, 819-826. http://dx.doi.org/10.4236/ojog.2015.514116 


\section{Introduction}

Induction of labor is performed in up to $25 \%$ of term pregnancies in developed countries. It has increased in Sweden from 7\% in the early 1990s to 16\% in 2012 [1] [2]. Labor induction involves increased risks for prolonged labor and operative delivery. These disadvantages are particularly prominent in primiparous women and women with an unripe cervix [3]. Among these subgroups, preinduction cervical ripening is necessary for a successful vaginal birth (VB). To our knowledge, there are no reports on labor induction with transcervical catheter compared with oral misoprostol in women with different parity and different Bishop scores (BS). The Cochrane reviewers do not report such subgroup analyses [4] [5].

Mechanical treatment with catheter for labor induction was first described in the 1860s [6]. The insertion of a transcervical catheter into the extraamniotic space separates the fetal membranes from the uterine wall, which stimulates the release of prostaglandins and oxytocin from the fetal membranes and uterine decidua [7]. These agents dissolve the glycosaminoglycan cross-links between the collagen fibrils in the cervical connective tissue, allowing for cervical effacement and dilatation [8]. The transcervical catheter may also stimulate neuroendocrine pathways interrelated with oxytocin synthesis and release, i.e. the Ferguson reflex [9].

Prostaglandin (PG) treatment for labor induction has been used since the 1980s [10]. Oral administration was not used because of presumed less efficacy and fear for gastrointestinal side effects. However, oral treatment with the PGE1 analogue misoprostol is well tolerated and is followed by a lower risk for uterine hyperstimulation and neonatal asphyxia compared to vaginal misoprostol [1] [5].

The choice of method is usually based on the caregiver's preference, the indication for labor induction, parity, BS and whether there is a medical history of a previous cesarean section (CS) or not.

The objective in this study was to investigate labor induction with transcervical catheter compared to treatment with oral misoprostol. The primary outcomes were VB within 24 hours and the CS rate. Secondary outcomes were the induction to vaginal delivery interval, as well as the rates of chorioamnionitis and neonatal asphyxia.

\section{Material and Methods}

The study was approved by the Ethics Board for Medical Sciences in Stockholm 2014/255-31. It was initiated as a quality contro project within the frames of the Medical Educational Programme at the Karolinska Institute. All clinical maternal and neonatal data were collected from original medical records in a tertiary hospital at the Department of Women's and Children's Health, Karolinska University Hospital, Solna, Sweden. Between January $1^{\text {st }}$ and December $31^{\text {st }} 2012$, 3952 women gave birth at the obstetric unit. Of these, 839 women i.e. $21.2 \%$ had labor induced with amniotomy, oxytocin infusion, vaginal PGE2 or transcervical catheter (Figure 1). According to the ICD-10 system and medical records 317 women, i.e. $37.8 \%$ of all inductions, underwent labor induction with transcervical catheter. Three women with intrauterine fetal death (IUFD) were excluded from the calculations. Accordingly, clinical data from 314 medical records were analyzed. A 22 Charrière Foley catheter (Meteko Instruments AB, Stockholm, Sweden) was inserted into the extraamniotic space at speculum investigation or digital examination according to the preference of the physician. After insertion, the catheter balloon was filled with water or $\mathrm{NaCl} 0.9 \% 50 \mathrm{~mL}$ and fastened to the thigh without traction. The position of the catheter was controlled by precoucious traction every $30 \mathrm{~min}$. Immediately after expulsed, amniotomy was performed. If not expulsed after 8 hours, the catheter was removed and amniotomy was performed according to the clinical guidelines. Oxytocin (Syntocinon ${ }^{\circledR}$, CD Pharma, Sweden) infusion $5 \mathrm{U} / 500 \mathrm{~mL}$ saline was started if no uterine contractions were observed within 1 hour after amniotomy, and immediately after catheter expulsion in the subgroup with prelabor rupture of the fetal membranes. The fetal heart activity was monitored with cardiotocography (CTG) 20 min before and after application and at labor onset. Between January $1^{\text {st }}$ and December $31^{\text {st }} 2013$, 3916 women gave birth at the obstetric unit. Of these, 819 women i.e. $20.9 \%$ had labor induced with amniotomy, oxytocin infusion, oral misoprostol, vaginal PGE2 or transcervical catheter (Figure 2). Oral misoprostol was introduced for labor induction in 2013, and 275 women had labor induced with this method. One participant was excluded because another method was used. Thus, 274 women i.e. $33.4 \%$ of all inductions were treated with oral misoprostol. Nine women with IUFD were excluded from the calculations. Accordingly, clinical data from 265 medical records were analyzed. Labor induction with oral misoprostol was carried out with the smallest available misoprostol (Cytotec ${ }^{\circledR}$, Pfizer, Sweden) tablet $200 \mu \mathrm{g}$ dissolved in $20 \mathrm{~mL}$ of water resulting in a concentration of $10 \mu \mathrm{g} / \mathrm{mL}$. A therapeutically adequate concentration of PGE1 was obtained [11]. A solution of $2.5 \mathrm{~mL}$ containing $25 \mu \mathrm{g}$ misoprostol was aspirated in a $3 \mathrm{~mL}$ syringe, whereupon the woman sprayed the solution 


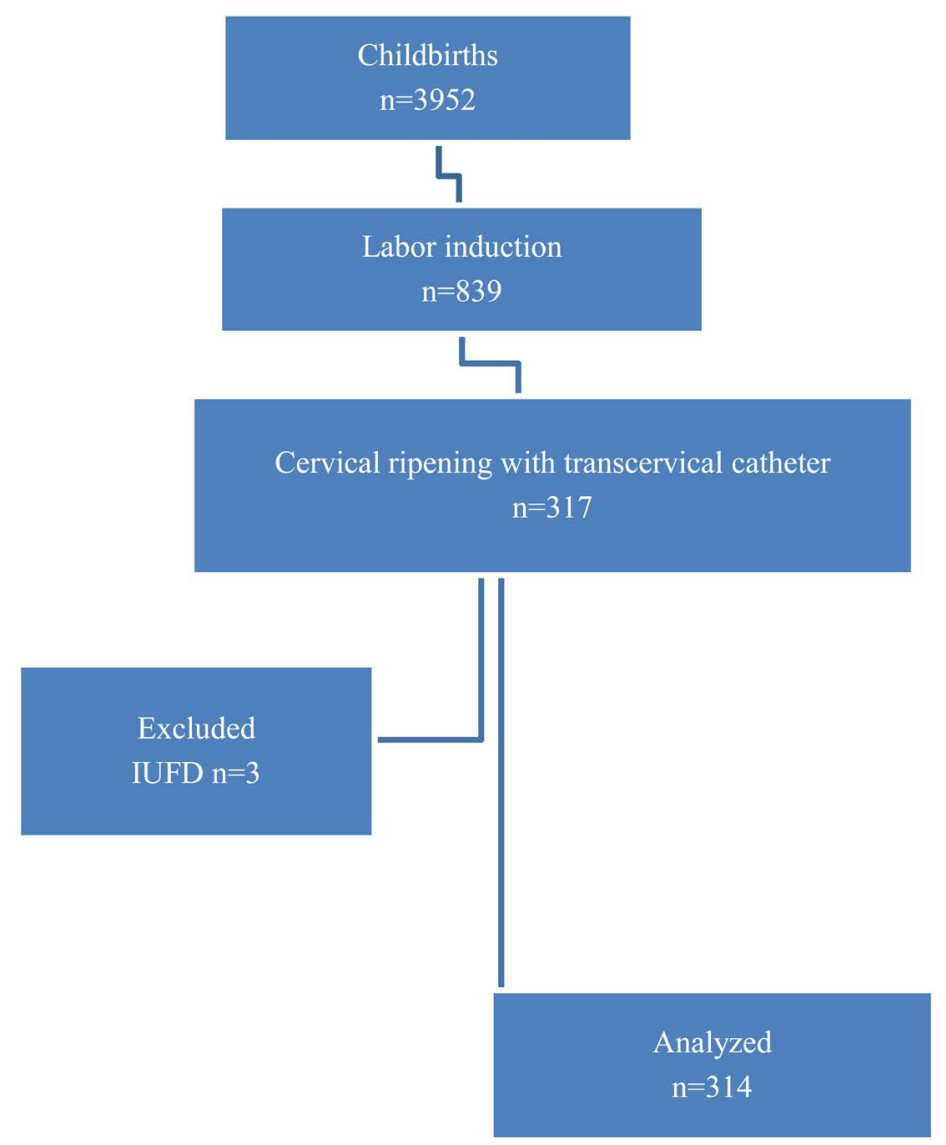

Figure 1. Assessment for eligibility 2012.

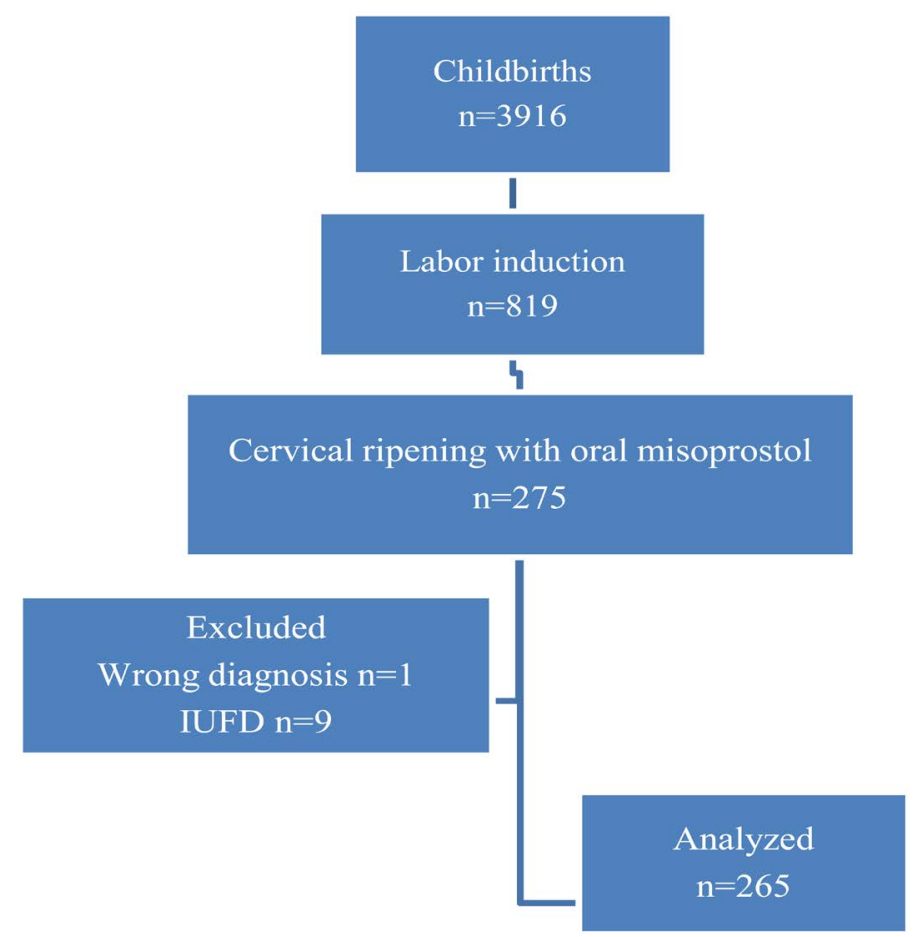

Figure 2. Assessment for eligibility 2013. 
in her mouth. Thereafter, water was aspirated in the syringe and was swallowed. The treatment was continued every 2 hour until labor onset up to a maximum of 8 doses. Fetal heart activity was monitored with CTG 20 min before each dose and at labor onset. If uterine contractions were observed, the following dose was postponed for 2 hours, given that active labor had not started. When a BS $>5$ was achieved, amniotomy was performed. Oxytocin (Syntocinon ${ }^{\circledR}$, CD Pharma, Sweden) infusion $5 \mathrm{U} / 500 \mathrm{~mL}$ saline was started for augmentation of labor according to the clinical guidelines, if there was no progress within 3 - 4 hours following amniotomy or spontaneous prelabor rupture of the fetal membranes.

Postterm pregnancy was defined as gestational age $42+0$ weeks [12]. Prelabor rupture of the fetal membranes was diagnosed visually and induction was initiated after 36 - 48 hours. The hypertensive disease group included women with essential hypertension, gestational hypertension or preeclampsia. The group imminent fetal distress included women with reduced fetal movements in combination with oligohydramniosis, antepartal pathological CTG or pathological umbilical arterial blood flow, decidual bleeding or Rhesus immunization. Psychosocial indications were fear of childbirth or normal pregnancy with pregnancy ailments. Maternal illness included women suffering from thrombophilia, malignancy, heart disease, or other chronic systemic diseases. The group fetal disease/indication included presumed macrosomia, anomalies or fetal cardiac arrhythmia. Women with gestational diabetes or diabetes mellitus were planned for induction at 38 - 40 weeks. Primiparous women $\geq 40$ years who had undergone in vitro fertilization (IVF) were planned for induction at 41 weeks. A long latency phase was defined as cervical dilatation $\leq 3 \mathrm{~cm}$ in spite of contractions lasting for 18 hours or more. In the duplex group, dichoriotic twin pregnancies with symmetric fetal growth were induced at 38 weeks and monochoriotic twin pregnancies with the same criteria at 37 weeks. Cervical ripening was categorized according to the Bishop scoring system monitoring 0 - 2 points for consistency, effacement, dilatation, position and station in the pelvic canal. A BS $>5$ was the criterion for a ripe cervix [13]. Hyperstimulation was defined as $>5$ contractions every 10 min during 20 min monitored by CTG. An Apgar score $<7$ at 5 min was the criterion for neonatal asphyxia [14].

All data were entered into the computer program Statistica, version AX, StatSoft, Inc, Tulsa, Oklahoma, US (2014). The continous data were analyzed with one-way analysis of variance (ANOVA). Assumptions for parametric statistics were tested by Levene's and Bartlett's tests. Statistical significance was set at $\mathrm{p}<0.05$. A power analysis was performed based on previous data [4] [5] [15]. We estimated the rate of VB $<24$ hours to $40 \%$ in the misoprostol group and assumed that $\mathrm{VB}<24$ hours would be achieved in $60 \%$ in the catheter group. Aiming at significance level $5 \%$ and $90 \%$ power, it would be necessary to include 125 women in each group.

\section{Results}

The indications for labor induction were similar between the groups (Table 1). Women suffering from IUFD were included in Table 1 and excluded from Tables 2-5. The demographic maternal data, i.e. age, parity, gestational age and rate of preterm gestational age $<37+0$ weeks ( 259 days), were comparable ( $p>0.05$ ). The mean BS was lower in the misoprostol group ( $<<0.001$, Table 2). Maternal outcomes are shown in Table 3. Transcervical catheter was followed by a higher rate of $\mathrm{VB}<24$ hours in primiparous women and in women with BS 3 - 4 ( $\mathrm{p}<0.001)$, but not in women with BS 0 - $2(\mathrm{p}=0.07)$. The CS rates were comparable in all groups ( $>$ $0.05)$. The instrumental delivery rates did not differ $(\mathrm{p}>0.05)$ and the main indication for an instrumental delivery with both methods was a prolonged second stage of labor ( $p>0.05$, data not shown).

The induction to vaginal delivery interval was 8 - 12 hours shorter with catheter ( $<<0.001$, Table 4$)$. In the misoprostol group, 24 women $(9.0 \%)$ had a transcervical catheter inserted and 6 women $(2.0 \%)$ were treated with vaginal PGE2 because of an unripe cervix with a BS $<5$ after the maximum 8 doses of misoprostol. No insertion in the catheter group was followed by any other method for labor induction.

The rates of chorioamnionitis were comparable with the two methods $(p>0.05)$. The neonatal birth weight and rates of newborns with an Apgar score $<7$ at 5 min were similar ( $p>0.05$, Table 5).

Among women with ruptured fetal membranes only (data not shown), VB $<24$ hours was achieved in $75.5 \%$ with catheter and $53.2 \%$ with oral misoprostol ( $p>0.05$ ). The CS rate with catheter was $22.6 \%$ compared to $19 \%$ with oral misoprostol $(\mathrm{p}>0.05)$.

\section{Discussion}

In this study, labor induction with transcervical catheter was compared to oral misoprostol treatment in primiparous 
Table 1. Indications for labor induction.

\begin{tabular}{cccc}
\hline Indication & Catheter $\mathrm{n}=317(\%)$ & Misoprostol $\mathrm{n}=274(\%)$ & $\mathrm{p}$ value \\
\hline Postterm & $67(21.1)$ & $64(23.3)$ & $\mathrm{p}>0.05$ \\
Prelabor rupture of fetal membranes & $73(23.0)$ & $41(15.0)$ & $\mathrm{p}>0.05$ \\
Hypertensive disease & $36(11.4)$ & $36(13.1)$ & $\mathrm{p}>0.05$ \\
Imminent fetal distress & $41(12.9)$ & $36(13.1)$ & $\mathrm{p}>0.05$ \\
Psychosocial & $27(8.5)$ & $24(8.8)$ & $\mathrm{p}>0.05$ \\
Maternal illness & $20(6.3)$ & $22(8.0)$ & $\mathrm{p}>0.05$ \\
Diabetes & $13(4.1)$ & $10(3.6)$ & $\mathrm{p}>0.05$ \\
Primiparous women $\geq 40$ years after IVF & $13(4.1)$ & $7(2.6)$ & $\mathrm{p}>0.05$ \\
Fetal disease/indication & $10(3.1)$ & $17(6.2)$ & $\mathrm{p}>0.05$ \\
Latency phase prolonged & $9(2.8)$ & $6(2.2)$ & $\mathrm{p}>0.05$ \\
Duplex & $5(1.6)$ & $2(0.7)$ & $\mathrm{p}>0.05$ \\
Intrauterine fetal death & $3(0.9)$ & $9(3.3)$ & $\mathrm{p}>0.05$ \\
\hline
\end{tabular}

Table 2. Demographic maternal data. Women suffering from intrauterine fetal death are excluded.

\begin{tabular}{cccc}
\hline Variable & Catheter $\mathrm{n}=314$ & Misoprostol $\mathrm{n}=265$ & p value \\
\hline Age (median and range) & $32(17-50)$ & $32(18-46)$ & $\mathrm{p}>0.05$ \\
Primiparous (\%) & $173(55.1)$ & $164(61.9)$ & $\mathrm{p}>0.05$ \\
Previous CS (\%) & $40(12.6)$ & $8(3.0)$ & $\mathrm{p}>0.05$ \\
Gestational age (median and range) & $39(34-42)$ & $39(34-42)$ & $\mathrm{p}>0.05$ \\
Gestational age $<$ 37 + 0 weeks (\%) & $4(1.3)$ & $13(4.9)$ & $\mathrm{p}>0.05$ \\
Bishop score all women (mean) & 2.6 & 2.1 & $\mathrm{p}<0.001$ \\
Bishop score 0 - 2 (\%) & $27(8.6)$ & $110(41.5)$ & $\mathrm{p}>0.05$ \\
Bishop score 3 - 4 (\%) & $190(60.5)$ & $128(48.3)$ & $\mathrm{p}>0.05$ \\
Bishop score $\geq 5(\%)$ & $97(30.9)$ & $27(10.2)$ & $\mathrm{p}>0.05$ \\
\hline
\end{tabular}

Table 3. Maternal outcomes. Women suffering from intrauterine fetal death are excluded.

\begin{tabular}{|c|c|c|c|}
\hline Variable & Catheter & Misoprostol & p value \\
\hline All women & $\mathrm{n}=314(\%)$ & $\mathrm{n}=265(\%)$ & \\
\hline Vaginal birth within 24 hours (\%) & 237 (75.5) & $141(53.2)$ & $\mathrm{p}<0.001$ \\
\hline Cesarean section (\%) & $71(22.6)$ & $51(19.2)$ & $\mathrm{p}>0.05$ \\
\hline Instrumental delivery (\%) & $41(13.0)$ & $48(18.1)$ & $\mathrm{p}>0.05$ \\
\hline Hyperstimulation & 0 & 0 & $\mathrm{p}>0.05$ \\
\hline Chorioamnionitis (\%) & $7(2.2)$ & $8(3.0)$ & $\mathrm{p}>0.05$ \\
\hline Uterine rupture & 0 & 0 & $\mathrm{p}>0.05$ \\
\hline Primiparous women & $\mathrm{n}=173$ & $\mathrm{n}=162$ & \\
\hline Vaginal birth within 24 hours (\%) & $136(78.6)$ & $66(40.2)$ & $\mathrm{p}<0.001$ \\
\hline Cesarean section & $51(29.4)$ & $41(25.0)$ & $\mathrm{p}>0.05$ \\
\hline Bishop score 0 - 2 & $\mathrm{n}=27$ & $\mathrm{n}=110$ & \\
\hline Vaginal birth within 24 hours (\%) & $16(59.2)$ & $47(42.7)$ & $\mathrm{p}=0.07$ \\
\hline Cesarean section (\%) & $8(29.6)$ & $30(27.3)$ & $\mathrm{p}>0.05$ \\
\hline Bishop score 3 - 4 & $\mathrm{n}=190$ & $\mathrm{n}=128$ & \\
\hline Vaginal birth within 24 hours (\%) & $141(74.2)$ & 78 (60.9) & $\mathrm{p}<0.001$ \\
\hline Cesarean section (\%) & $46(24.2)$ & $19(14.8)$ & $\mathrm{p}>0.05$ \\
\hline
\end{tabular}


Table 4. Induction to vaginal delivery intervals in hours (mean \pm standard error). Women suffering from intrauterine fetal death and women delivered by cesarean section are excluded.

\begin{tabular}{|c|c|c|c|}
\hline Variable & Catheter $n=243$ & Misoprostol $n=214$ & p value \\
\hline All women & $11.8 \pm 0.3$ & $21.6 \pm 0.6$ & $\mathrm{p}<0.001$ \\
\hline Primiparous women & $13.0 \pm 0.4$ & $24.9 \pm 0.8$ & $\mathrm{p}<0.001$ \\
\hline Bishop Score 0 - 2 & $13.1 \pm 1.3$ & $24.1 \pm 0.8$ & $\mathrm{p}<0.001$ \\
\hline Bishop Score 3 - 4 & $11.9 \pm 0.4$ & $20.1 \pm 0.8$ & $\mathrm{p}<0.001$ \\
\hline
\end{tabular}

Table 5. Neonatal outcomes.

\begin{tabular}{cccc}
\hline Variable & Catheter $\mathrm{n}=314$ & Misoprostol $\mathrm{n}=265$ & p value \\
\hline Birth weight $(\mathrm{g})($ mean \pm SD) & $3495 \pm 568$ & $3472 \pm 579$ & $\mathrm{p}>0.05$ \\
Apgar score $<7$ at $5 \min (\%)$ & $7(2.2)$ & $4(1.5)$ & $\mathrm{p}>0.05$ \\
\hline
\end{tabular}

women and women with an unripe cervix, who were at high risk for unsuccessful labor induction, resulting in prolonged labor and CS. An uncomplicated first childbirth is the primary positive prognostic factor for a later successful delivery [16]. The most common indications for labor induction were postterm pregnancy, prelabor rupture of the fetal membranes, hypertensive disease and imminent fetal distress. The demographic maternal data were comparable, except for the mean BS, which was lower in the misoprostol group. This was not a bias since subgroup analyses for different BS were performed.

Transcervical catheter was followed by VB $<24$ hours more frequently in primiparous women and women with BS 3 - 4 compared to oral misoprostol. The lack of significance in women with BS 0 - 2 could be explained by the limited sample size. The CS rates were comparable with the two methods in all groups, and the instrumental delivery rates were comparable. The major indication for a CS and an instrumental delivery with both methods was prolonged labor. The second indication was fetal distress, defined as a pathologic CTG pattern or a pathological fetal scalp lactate.

It was emphasized in clinical practice that cervical ripening with prostaglandins was hazardous among women with a previous CS because of an increased risk for uterine scar rupture [1] [5]. Forty women (12.6\%) with a previous CS were treated with a transcervical catheter and 8 women (3.0\%) with a previous CS were treated with oral misoprostol due to the individual physician's choice. However, no uterine ruptures were observed in our material. Labor induction with transcervical catheter has been related to an increased incidence of chorioamnionitis [17]. However, the incidence of chorioamnionitis in the present study was lower than the previously reported $15.2 \%$ after catheter and $14.3 \%$ after oral misoprostol [18]. The rates of chorioamnionitis in the catheter and oral misoprostol groups were comparable, and did not differ from the general incidence in the obstetric unit, being 1.3\% in 2012 and 2013.

Strengths with this study were that data were collected from original medical records and the large sample size. The retrospective character was in itself a limitation.

The costs were low with both methods. In average, 5 doses of misoprostol were required to achieve a BS allowing for amniotomy. The cost for 5 fresh doses of misoprostol was $€ 9.2$ and the cost for 1 Foley catheter was $€ 2.2$.

There are, to our knowledge, very few reports on labor induction with transcervical catheter compared to treatment with oral misoprostol. Abramovici et al. investigated labor induction with oral misoprostol $50 \mu \mathrm{g}$ every 4 hours up to a maximum of 6 doses in 98 women compared with transcervical catheter up to 12 hours in 99 women. VB $<24$ hours was obtained in $84.8 \%$ after catheter versus $68.4 \%$ after misoprostol in all women, and $82.5 \%$ after catheter versus $53.4 \%$ after misoprostol in primiparous women. The authors concluded that misoprostol was as effective as catheter in multiparous women, but less efficacious in primiparous women [18]. Goonewardene et al. reported on labor induction in postterm pregnancy with oral misoprostol $25 \mu$ g every 4 hours for 24 hours in 74 women compared with catheter for 24 hours in 78 women. VB $<24$ hours was not measured. The authors concluded that catheter was more effective than oral misoprostol [19]. The CS rates in the present study were comparable with those reported by Abramovici et al. [18], but lower after misoprostol than reported by Goonewardene et al. [19]. In the ongoing multicenter PROBAAT-II study, initiated 2013 in the Netherlands, labor induction with a catheter for 4 days is compared to treatment with oral misoprostol $50 \mu \mathrm{g}$ 
every 4 hours up to 3 doses a day during 4 days [20].

In conclusion, labor induction with transcervical catheter resulted in a higher rate of VB $<24$ hours and an 8 12 hours shorter induction to vaginal delivery interval in primiparous women and women with an unripe cervix. This was obtained without increasing the rates of CS, chorioamnionitis or neonatal asphyxia.

\section{Conflicts of Interests}

None.

\section{References}

[1] World health Organization (2011) WHO Recommendations for Induction of Labour. World Health Organization, Geneva.

[2] The Swedish National Board of Health and Welfare (2013) Pregnancies, Deliveries and Newborn Babies. The Swedish Medical Birth Register 1973-2012. www.socialstyrelsen.se

[3] Caughey, A.B., Sundaram, V., Kaimal, A.J., Cheng, Y.W., Gienger, A., Little, S.E., et al. (2009) Maternal and Neonatal Outcomes of Elective Induction of Labor (Review). Evidence Report/Technology Assessment, 176, 1-257.

[4] Jozwiak, M., Bloemenkamp, K.W.M., Kelly, A.J., Mol, B.W.J., Irion, O. and Boulvain, M. (2012) Mechanical Methods for Induction of Labour (Review). Cochrane Database of Systematic Reviews, 2012, Article ID: CD001233. http://dx.doi.org/10.1002/14651858.cd001233.pub2

[5] Alfirevic, Z., Aflaifel, N. and Weeks, A. (2014) Oral Misoprostol for Induction of Labour. Cochrane Database of Systematic Reviews, 2014, Article ID: CD001338. http://dx.doi.org/10.1002/14651858.cd001338.pub3

[6] Woodman, W.B. (1863) Induction of Labor at Eight Months and Delivery of a Living Child in Less than Four Hours by Dr Barnes’ Method. Lancet, 81, 10-11.

[7] Challis, J.R. and Smith, S.K. (2001) Fetal Endocrine Signals and Preterm Labor. Biology of the Neonate, 79, $163-167$.

[8] Hertelendy, F. and Zakar, T. (2004) Prostaglandins, the Myometrium and the Cervix. Prostaglandins, Leukotrienes \& Essential Fatty Acids, 70, 207-222. http://dx.doi.org/10.1016/j.plefa.2003.04.009

[9] Ferguson, J.K. (1941) A Study of the Motility of the Intact Uterus at Term. Surgery, Gynecology, and Obstetrics, 73, 359-366.

[10] Ulmsten, U., Wingerup, L. and Ekman, G. (1983) Local Application of Prostaglandin E2 for Cervical Ripening or Induction of Term Labor. Clinical Obstetrics \& Gynecology, 26, 95-105. http://dx.doi.org/10.1097/00003081-198303000-00013

[11] The Swedish Medical Products Agency (2012) Laboratory Study on Preparation of Cytotec for Labour Induction. Laboratory Report No. 297: 2012/507712.

[12] World Health Organization (1977) WHO: Recommended Definitions, Terminology and Format for Statistical Tables Related to the Perinatal Period and Use of a New Certificate for Cause of Perinatal Deaths. Acta Obstetricia et Gynecologica Scandinavica, 56, 247-253.

[13] Bishop, E.H. (1964) Pelvic Scoring for Elective Induction. Obstetrics \& Gynecology, 24, 266-268.

[14] Apgar, V. (1953) A Proposal for a New Method of Evaluation of the Newborn Infant. Current Researches in Anesthesia \& Analgesia, 32, 260-267. http://dx.doi.org/10.1213/00000539-195301000-00041

[15] Thorbiornson, A., Vladic, T., Vladic Stjernholm, Y. (In Manuscript) Advantage for Labor Induction with Oral Prostaglandin-E1 Compared with Vaginal Prostaglandin-E2 in Primiparous Women and Women with an Unripe Cervix.

[16] Spong, C.Y., Berghella, V., Wenstrom, K.D., Mercer, B.M., Saade, G.R. (2012) Preventing the First Cesarean Delivery: Summary of a Joint Eunice Kennedy Shriver National Institute of Child Health and Human Development, Society for Maternal-Fetal Medicine and American College of Obstetricians and Gynecologists Workshop. Obstetrics \& Gynecology, 120, 1181-1193.

[17] Heinemann, J., Gillen, G., Sanchez-Ramos, L. and Kaunitz, A.M. (2008) Do Mechanical Methods of Cervical Ripening Increase Infectious Morbidity? A Systematic Review. American Journal of Obstetrics and Gynecology, 189, 177-188. http://dx.doi.org/10.1016/j.ajog.2008.05.005

[18] Abramovici, D., Goldwasser, S., Mabie, B.C., Mercer, B.M., Goldwasser, R. and Sibai, B.M. (1999) A Randomized Comparison of oral Misoprostol versus Foley Catheter and Oxytocin for Induction of Labor at Term. American Journal of Obstetrics and Gynecology, 181, 1108-1112. http://dx.doi.org/10.1016/s0002-9378(99)70090-6

[19] Goonewardene, M., Kumara, D.M.A., Ziard, M.H. and Bhabu, B. (2014) Intracervical Foley Catheter vs Oral Misoprostol for Preinduction Cervical Ripening of Postdated Pregnancies. Sri Lanka Journal of Obstetrics and Gynae- 
cology, 3, 66-70. www.slcog.lk

[20] Ten Eikelder, M.L., Neervoort, F., Rengerink, K.O., Jozwiak, M., de Leeuw, J.W., de Graaf, I., et al. (2013) Induction of Labour with a Foley Catheter or Oral Misoprostol at Term: The PROBAAT-II Study, a Multicenter Randomized Controlled Trial. BMC Pregnancy and Childbirth, 13, 183. http://dx.doi.org/10.1186/1471-2393-13-183 